The University of San Francisco

USF Scholarship: a digital repository @ Gleeson Library |

Geschke Center

Media Studies

College of Arts and Sciences

2012

\title{
Shifts in the Architecture of the Nationwide Health Information Network
}

L. Lenert

D. Sundwall

Michael E. Lenert

University of San Francisco, melenert@usfca.edu

Follow this and additional works at: http://repository.usfca.edu/ms

Part of the Digital Communications and Networking Commons, and the Public Health Commons

\section{Recommended Citation}

Lenert, L., Sundwall, D., \& Lenert, M. E. (2012). Shifts in the architecture of the Nationwide Health Information Network. Journal of the American Medical Informatics Association : JAMIA, 19(4), 498-502. http://doi.org/10.1136/amiajnl-2011-000442

This Article is brought to you for free and open access by the College of Arts and Sciences at USF Scholarship: a digital repository @ Gleeson Library | Geschke Center. It has been accepted for inclusion in Media Studies by an authorized administrator of USF Scholarship: a digital repository @ Gleeson Library | Geschke Center. For more information, please contact repository@usfca.edu. 


\title{
Shifts in the architecture of the Nationwide Health Information Network
}

\author{
Leslie Lenert, ${ }^{1}$ David Sundwall, ${ }^{2}$ Michael Edward Lenert ${ }^{3}$
}

1 Department of Medicine, University of Utah, Salt Lake City, Utah, USA

${ }^{2}$ Department of Family and Community Medicine, University of Utah School of Medicine, Salt Lake City, Utah, USA

${ }^{3}$ Department of

Communications, University of San Francisco, San Francisco, California, USA

\section{Correspondence to}

Dr Leslie Lenert, Department of Medicine, University of Utah, 30 North 1900 East, Room 4C104, Salt Lake City, UT 84132, USA; eslie.lenert@gmail.com

Received 24 June 2011 Accepted 23 December 2011 Published Online First 21 January 2012

\section{ABSTRACT}

In the midst of a US $\$ 30$ billion USD investment in the Nationwide Health Information Network (NwHIN) and electronic health records systems, a significant change in the architecture of the NwHIN is taking place. Prior to 2010, the focus of information exchange in the NwHIN was the Regional Health Information Organization (RHIO). Since 2010, the Office of the National Coordinator (ONC) has been sponsoring policies that promote an internetlike architecture that encourages point to-point information exchange and private health information exchange networks. The net effect of these activities is to undercut the limited business model for $\mathrm{RHIOs,}$ decreasing the likelihood of their success, while making the NwHIN dependent on nascent technologies for community level functions such as record locator services. These changes may impact the health of patients and communities. Independent, scientifically focused debate is needed on the wisdom of ONC's proposed changes in its strategy for the NwHIN.

\section{INTRODUCTION}

This article explores the changes in policy toward health information exchange under the Obama administration. It postulates that the forces unleashed with policy shifts are likely to result in a dramatic reduction in the role of regional health information organizations (RHIOs) in the Nationwide Health Information Network (NwHIN). In the place of RHIOs, a new internet-like model of health exchange is being tested and developed based on technologies such as the DIRECT Project. We write this article to prompt a pause for reflection on the wisdom of this approach. We describe the history of RHIOs, the value of RHIOs to patients and communities, the changes in the policies of the Office of the National Coordinator (ONC), and likely the consequences of these changes. Based on this analysis we call for an open debate and the development of scientific consensus before irrevocable commitment to one model or another for the NwHIN is made.

\section{REGIONAL HEALTH INFORMATION ORGANIZATIONS}

Prior to and for the first year of implementation of the Obama administration's US\$30 billion investment in health information technology through the Health Information Technology for Economic and Clinical Health (HITECH) Act, the USA has been pursuing the development of its national health information architecture through community level information exchange within regional healthcare markets. This approach has been called a 'bottom up' strategy by Coiera (in contrast to the 'top down' centralized strategy used in the UK by the National Health Service $\left.(\mathrm{NHS})^{1}\right)$. RHIOs were the focus of efforts, defined as:

An organization that brings together health care stakeholders within a defined geographic area and governs health information exchange among them for the purpose of improving health and care in that community according to nationally recognized standards. ${ }^{2}$

Among the goals of RHIOs are support for network connectivity or virtual private network capability, data exchange, use agreements for clinical data, and regional security services. The design model of a nationwide system for health data exchange for the USA, as late as April 2010, well into the implementation of HITECH, focused on integration of regional exchanges, Federal healthcare entities, and other large integrated healthcare delivery systems such as Kaiser Permanente, into a system linked by common protocols. ${ }^{3}$ By organizing exchange around communities and health referring areas, RHIOs offered the potential to optimize utilization of existing resources while preserving resilience through local variation and autonomy. ${ }^{1}$

RHIOS are typically not-for-profit organizations that have many of the characteristics of a public utility enterprise. They are neutral organizations providing open access to participants in the region, most with the goals of providing service to all providers in the community (as opposed to random or selective inclusion), analogous to the universal service requirements of most public utilities. RHIOs exist for the public good of information exchange across a community, in much the same way that an electrical company or cable company provides a service perceived as a public good However, unlike public utilities, they do not have a monopoly on provision of services within their region, which can create economic problems, as discussed below. Consistent with their role as community led organizations, the functions of RHIOs differ based on community needs.

\section{OTHER MODELS FOR NATIONAL HEALTH INFORMATION EXCHANGE}

The approach taken in the USA is unique. Other countries have pursued alternative, more centralized options where government entities have primary responsibility for information exchange. In the UK, the NHS has managed the development of standards, the production of electronic health records systems and services, connectivity, and software services for data exchange at a national 
level. ${ }^{4}$ Despite widespread success with office-based electronic records systems, the development of integrated nationwide software systems for health data exchange has proven too complex a task for government ${ }^{5}$ and, as a result, the UK may evolve toward a provincial (NHS region) strategy, ${ }^{6}$ with one records system for each region with overlapping technologies and standards. This is similar to the approach taken in Australia and Canada, which Coiera calls 'middle out,' 1 and which focuses on provincial governments leading implementation of both electronic records systems and health data exchange. A critical element of the middle out approach is moving development efforts to a semi-private government funded corporation. These entities manage the development of common software systems and standards that support reuse of technology and integration across provinces, without the encumbrances of a government agency. The theoretical advantages of a 'middle out' approach are flexibility in standards that support evolution and innovation, along with a greater degree of responsiveness to local needs, particularly practitioner needs, ${ }^{7}$ than may be possible with a national effort. However, the Canadian and Australian national systems are still under development, so the wisdom of the regional approach is an open question.

\section{WHY RHIOS ARE IMPORTANT}

An example of a 'public good' implemented within many RHIOs is the potential capability to quickly and automatically locate and retrieve most relevant electronic health records for a patient. This capability could be thought of as a public service-like function, readily available to all authorized providers but not necessarily economically viable to create or self-supporting

The ability to quickly and automatically locate most relevant electronic records for a patient was a critical design feature of early RHIOs. ${ }^{8}$ Between 2005 and 2007, $\mathrm{ONC}^{9}$ and the Markle Foundation, through a group called 'Connecting for Health,'10 developed and tested prototype designs for health information exchanges that focused on regional, and later inter-regional, exchange of health information and patient records. To be able to retrieve electronic health records for an individual in a region, RHIOs had to maintain two critical components:

- A list of the vast majority of individuals in the community with linkages to the different medical record numbers used by different medical providers and health systems (called a Master Patient Index, or MPI), and

- An index or a web service capable of determining the locations and types of medical records across the community for a particular patient (called a Record Locator Service, or RLS).

How common is it for medical professionals to need to retrieve summaries of care for patients? In emergency departments (ED) and consultative medicine, data from patient records are often needed to provide optimal care and reduce redundant diagnostic testing, but such data are all too often not available. Patients who visited multiple EDs accounted for $22 \%$ of all visits to EDs in the central Indiana region. ${ }^{11}$ In clinical consultations, Gandhi and colleagues reported $68 \%$ of specialists did not receive prior information from referring primary care physicians, ${ }^{12}$ let alone records from other physicians in the community. Moreover, it is relatively easy to find compelling clinical use cases for access to records from other institutions. For example, in the UK, a motivating example for the creation of its summary record system was the case of journalist Penny Campbell, who died of sepsis related to a recent procedure after seeing eight different physicians for her symptoms. ${ }^{13}$
At present, however, retrieval and use of information from remote systems is an at-the-point-of-care clinical workflow issue that is subject to failures from many technical causes. ${ }^{14} 15$ In the USA, in one RHIO focused on Medicaid and indigent patients, retrievals occurred in just $2.6 \%$ of cases. ${ }^{16}$ Similar results were seen in a UK study of access to 'summary records' within an NHS demonstration project-access occurred in just $4 \%$ of cases. Qualitative studies subsequently explored the rationale for the low rate of access. Researchers identified physician beliefs of a low probability of finding information as the primary reason for not using the system. Interestingly, when patients had summaries available online, summaries were accessed frequently (22\% of encounters). ${ }^{17}$ Johnson and colleagues also observed that access to regional health information exchanges in EDs increased from $6.8 \%$ to about $15 \%$ among patients with return visits. ${ }^{18}$ Therefore, it seems likely that if RLSs were widely available, they would be used in clinical practice.

Maintaining a community level RLS capable of producing a summary of care across different computing environments of differing healthcare organizations is complex. ${ }^{19}$ However, once the initial work is performed, MPI and RLS technology can support a wide range of quality improvement and population health activities at a community level that are potentially valuable, if not economically viable, services that might include medication resolution, reminders to patients of needed preventive services, and alerts for public health issues. ${ }^{19} 20$ These community level activities, and others, are a focus of ongoing work in the ONC's Beacon Communities Program.

RHIOs also serve other functions in communities that may be difficult to duplicate at a state or national level. Foremost among those purposes is a forum for developing consensus-based data use and reciprocal support agreements (DURSAs) among healthcare data across entities within a region. ${ }^{21}$ DURSAs contain the policies related to use and re-use of data for research purposes, system access, security, patient access, and consent. DURSA agreements play an important role in the dynamic security of data exchange, specifying security levels, logging and tracking of transactions, and responses to findings of malicious software.

\section{CHANGES IN THE STRATEGY FOR IMPLEMENTATION OF THE NWHIN}

RHIOs were the foundation of government-led health information exchange efforts under the Bush administration, expanding between 2005 and 2008 to over 100 active organizations. ${ }^{22}$ The achievements of the RHIOs in this period were limited because of inadequate funding and problems with sustainability. ${ }^{23}$ Under the Obama administration, RHIOs have had mixed support. The HITECH Act did not provide direct funding for RHIOs and the ONC did not renew funding from its congressional appropriations to support existing RHIOs. In addition, the Centers for Disease Control terminated funding which supported collaborations between public health departments and RHIOs. In its place, the ONC, through HITECH, funded states to develop and implement comprehensive information exchange plans. The plans of some states included existing RHIOs (eg, Indiana and Delaware), while the plans of other states abandoned existing RHIOs and set up new entities controlled by political allies of the current state governments (eg, California). In addition to funding states, the ONC also funded the Beacon Communities Program, a grant program supporting communities with advanced levels of health information technology to adopt community-wide health improvement efforts. Some Beacon Communities opted to form RHIOs 
or use existing RHIOs to implement their objectives. Overall, the number of RHIOs has grown to more than 200 in 2011, even as concerns related to their financial viability continue. ${ }^{23}$

However, RHIOs no longer play the central role in NwHIN's architecture that they once did. In the place of RHIOs, the ONC has adopted and described in its 2011-2015 Strategic Plan, ${ }^{24}$ a web-based model for health information exchange with multiple types of networks in a region and direct point-to-point exchange between providers when necessary or convenient. Quoting from page 14 the plan:

\section{Many sustainable exchange options already exist for certain providers and certain types of health information. Some hospital networks and group provider practices have found a business case for investing in information exchange within their networks. Vendors of EHR [electronic health record] systems are developing 'information networks' for their customers. Communities are creating health information networks to facilitate information sharing among providers. Diagnostic lab companies and electronic prescription companies offer services that enable exchange of specific pieces of health information for providers able to pay for them.}

As stated in the plan, hospital groups, vendors of electronic health records, and laboratory vendors all have a role in health information exchange and these various types of private networks are equal partners with community-based exchanges (ie, RHIOs) in the ONC's new model. The approach is internetlike in its promotion of point-to-point information exchange through standards and interoperability initiatives such as DIRECT. It will also rely upon web services such as directories for identification of providers and facilities that are analogous to the Domain Name Services (DNS) model underlying the internet, along with internet-based security models. These yet to be constructed services will allow users to look up how to send data to providers and will specify security operations. The advantage of this approach is that it may radically lower the cost of connections for data exchange between parties for 'push' transmission through elimination of expensive custom interfaces. It may also speed up the process of health information exchange, making it potentially possible to require health information exchange to earn incentives under the administration's Meaningful Use policy.

The ONC's new plan also relies upon states to perform several tasks that were formerly the role of RHIOs, as stated on page 16:

States will support providers by building... provider directories, record locator services, and master patient indices... enhancing the information exchange capabilities of key trading partners.

The plan does not describe how states would finance maintenance of directories and record locator services or how they would implement a record locator service without RHIOs. At a technical level, these capabilities might be developed, without RHIO-like organizations, using alternative architectures described in a 2010 report by the President's Council of Advisors on Science and Technology (PCAST) entitled 'Realizing the Full Potential of Health Information Technology to Improve the Healthcare of Americans: The Path Forward. ${ }^{25}$ The approach seeks to apply the differential between the growth of the power of computational systems and of software engineering to solve the problem of the interoperability of health information technology systems as first described by Stead and colleagues. ${ }^{26}$ They propose using 'referential standards' (flexible adaptable semantics) implemented as markup languages, as tools for interoperability and information retrieval. Based on this model, the PCAST report called for the abandonment of contemporary softwarebased architectures for health information exchange provided by RHIOs. Instead, the report called for a new architecture supporting community services (and research) through Googlelike search engines that indexed exposed medical data, marked with referential languages for semantic interoperability and security for retrieval. Medical data would be retrieved through a network of data-element access services that maintained indexes of data types and locations for individuals. ${ }^{25}$ Acknowledged as visionary by health IT leadership, but also widely criticized as impractical for implementation at this time, ${ }^{27} 28$ the PCAST report underlies ONC's demotion of RHIOs in its pantheon of health information exchange mechanisms.

\section{THE RISE OF PRIVATE NETWORKS FOR HEALTH INFORMATION EXCHANGE}

The de-emphasis on RHIOs in NwHIN also has opened the door for private enterprises to build networks for connectivity for information exchange. Through professional organizations such as the American Medical Association and the American Academy of Family Practice, and networks associated with electronic health record vendors, vast new private exchanges may be created. ${ }^{29}$ Importantly, these networks will be largely independent of communities and cross state boundaries. The vendors of private networks, such as SureScripts ${ }^{29}$ and VisionShare, ${ }^{30}$ have a significant advantage over RHIOs that attempt to follow a public utility-like model. They are not obligated to provide other critical services necessary for a community health system or even universal connectivity for the region. They can recruit participants based on favorable economics, reaping profits without having to meet the requirements for undertaking the truly difficult tasks in health information exchange. Further, health information exchange with business partners on private networks will likely meet proposed Stage 2 criteria for Meaningful Use incentives.

\section{HOW THE ONC'S PROPOSED CHANGES THREATEN RHIOS}

Some have argued that the ONC's new strategic plan does not explicitly undercut RHIOs. ${ }^{31}$ However, if exchange of data and meaningful use certification can be achieved without connecting to a RHIO, there may be little reason for providers to join one, particularly if RHIOs have higher costs. The threat of competition in health information exchange from DIRECT and private networks is significant. Of the numerous RHIOs created between 2005 and the present, only a small proportion have sustainable business models. ${ }^{23}$ Financially viable RHIOs tend to be funded by fees for initiation and clinical exchange services provided to hospitals and practicing physicians ${ }^{32}$ and thus have had to compete with other private sector entities (eg, hospital chains, clinical laboratories, and insurance claim conveyance organizations) for delivery of data exchange services.

The changes in the ONC's strategy expose the primary weakness of the RHIO sustainability model: namely, the mismatch between the public utility-like mission adopted by many RHIO organizations and the requirements for free market success for sustainability. RHIOs that subsidize connectivity services and provide universal access to their networks along with other services for the good of the community are operating like public utilities. Their actions are driven not so much by sustainability as by public good. However, few RHIOs have had monopolies on health information exchange in their region, and as a consequence competition for health information exchange services drives the price of those services to their cost, making it 
difficult to subsidize other information exchange activities conducted for the public good.

RHIOs' sustainability problems parallel issues that have arisen with the privatization of public utilities in the USA. Beginning in the early 1980s, the USA began engaging in a series of experiments where public utility model enterprises such as electricity and notably postal and telephone services, were either privatized or forced to compete in open markets. The private sector took over the most economically viable portions of the market, choosing the lowest cost customers and avoiding costs for difficult to serve customers and avoiding the cost of community-wide benefits. This ultimately causes public utilities to cease operations or to adapt to a for-profit model, at the cost of loss of the for-public-benefit aspects of the enterprise. For example, competition with private entities has recently forced the US Postal Service to close rural offices and give up Saturday deliveries. When a public utility model industry is privatized, new models of regulation ${ }^{33}$ or incentives for businesses ${ }^{34}$ may be needed to sustain useful, but unprofitable services delivered 'for the good of the community.'

The impact of DIRECT and of private networks for health information exchange may have been underestimated by the ONC because of a failure to consider the effects of disruptive innovations on markets. Disruptive innovations, according to Christensen, are new approaches or technologies that, while initially offering lower performance than established methods, have far lower entry barriers, opening up new markets of greater scale, in which the disruptive technologies eventually grow to equal and often surpass the capabilities of incumbents. ${ }^{35} 36$ In this setting, disruptive innovations typically take over a market displacing established vendors.

\section{REVERSING COURSE IF NECESSARY}

Is there a way to preserve RHIOs, given the changes already implemented by ONC? Meaningful Use regulations currently provide substantial incentives for providers and hospitals to participate in health data exchange (up to US\$44000 for Medicare and US\$6300 for Medicaid providers, and on the order of millions of dollars for hospitals). To support RHIOs, Meaningful Use regulations could require hospitals and providers to make a connection through a RHIO-like exchange, one that complies with set standards for interoperability and community level services, and is subject to some level of oversight, where such an exchange is available. By requiring connectivity through a 'certified exchange' (to be defined in federal regulation), such exchanges would have licensed monopolies and would be able to charge connectivity and data exchange fees that would provide a viable economic model to support their public utility-like functions.

\section{SLOWING DOWN TO SPEED UP}

The success of the ONC's strategy depends on the ability of the PCAST report computationally powered technologies to replace software powered technologies that underlie present designs for MPI and RLS regional services. While the PCAST approach is innovative, the superior functionality of the approach is, at this time, only a hypothesis - the feasibility of and the time required to develop deployable software based on the architecture is unknown. Premature retiring of the RHIO model through shifts in funding and increased competition from private data exchange networks could result in serious long term loss of the community level functions that are critical to the delivery of high quality, cost effective care.
At this point, the decision to switch the overarching design of the NwHIN from a RHIO-based model to a PCAST-like approach is strongly linked to the Obama administration. The PCAST report was produced by a committee formed by the Science and Technology Directorate of the White House and commentaries upon it were produced by the ONC's politically appointed Health Policy Federal Advisory Committee. What is needed is a non-partisan discussion of the wisdom of changing the architecture of the NwHIN from one based on RHIOs to a more internet-like approach. Failure to adequately discuss the proposed changes might lead to a reversal of policies after the 2012 election if a different political party comes to power, with accordant wasting of valuable resources. The best organizations to lead this debate might be the Institute of Medicine and the National Academy of Sciences with their traditions of independence and history of valuable contributions in directing national policies for health information technology. If the scientific consensus is that an internet-like architecture is the best option, then additional steps may be needed to preserve the value of the NwHIN to communities, and to support the governance and security roles played by RHIOs as a 'public good.'

Achieving the great potential of the NwHIN, particularly its potential to connect health information on individuals and populations at a community-wide level, requires ongoing statesmanship and collaboration. What is important to the progress of any truly great and complex endeavor, such as we face with the development of the NwHIN, is that the activity be driven by non-partisan principles through rational, cross administration planning and execution. The great technical achievements of our country, such as moon-traveling rockets and ocean-linking canals, did not belong to one political party or another, but were sustained across transitions of power. Success with the NwHIN demands the same non-partisan commitment to achievement of a common vision.

Acknowledgments The authors would like to thank Kathleen Handziuk for her editorial assistance.

Competing interests Dr Lenert is a consultant to IBM Federal Systems and United Biosource Corporation. Dr Sundwall is a consultant to Abbott Laboratories.

Contributors LL conceived of and authored the initial versions of this manuscript and contributed to subsequent revisions. DS contributed to the conceptual development of initial versions of the manuscript and helped refine subsequent drafts. MEL contributed to the conceptual development of the manuscript.

Provenance and peer review Not commissioned; externally peer reviewed.

\section{REFERENCES}

1. Coiera E. Building a National Health IT System from the middle out. J Am Med Inform Assoc 2009;16:271-3.

2. The National Alliance for Health Information Technology. Report to the Office of the National Coordinator for Health Information Technology on Defining Key Health Information Technology Terms. Washington DC: Office of the National Coordinator for Health Information Technology, 2008. http://healthit.hhs.gov/portal/server.pt/ gateway/PTARGS $0 \quad 10741848133 \quad 0 \quad 0 \quad 18 / 10 \quad 2$ hit terms.pdf laccessed 18 Oct 2011).

3. Office of the National Coordinator. Nationwide Health Information Network (NHIN) Exchange Architecture Overview v. 0.9. Department of Health and Human Services, 2010. http://healthit.hhs.gov/portal/server.pt/gateway/ PTARGS $01074184813300 \quad$ 18/10 2 hit terms.pdf (accessed 17 Jan 2011).

4. Payne TH, Detmer DE, Wyatt J $\overline{\mathrm{C}}$, et al. National-scale clinical information exchange in the United Kingdom: lessons for the United States. J Am Med Inform Assoc 2011; 18:91-8

5. Comptroller and Auditor General. The National Programme for IT in the NHS: An Update on the Delivery of Detailed Care Records Systems. London: National Audit Office, 2011. http://www.nao.org.uk/idoc.ashx?docld=64845779-a17b-4771-a5494f9518a17d15\&version=-1 (accessed 17 Oct 2011).

6. Versel N. UK scrapping national health IT network. InformationWeek 2011. http:// www.informationweek.com/news/healthcare/policy/231300185 laccessed 17 Oct 2011). 
7. Zimlich E, Rosenblum R, Salzberg CA, et al. Lessons from the Canadian national health information technology plan for the United States: opinions of key Canadian experts. J Am Med Inform Assoc 2012;19:453-9.

8. Vest JR, Gamm LD. Health information exchange: persistent challenges and new strategies. J Am Med Inform Assoc 2010;17:288-94.

9. Rishel W, Riehl V, Blanton C. Summary of the NHIN Prototype Architecture Contracts. Washington DC: Office of the National Coordinator for Health IT, 2007. http://www.hhs.gov/healthit/healthnetwork/resources/summary_report on nhin Prototype architectures.pdf (accessed 17 Oct 2011).

10. Connecting for Health. Health Information Exchange: Architecture Implementation Guide. Markle Foundation, 2006. http://www.markle.org/sites/default/files/ T2 Healthlnfo.pdf (accessed 17 Oct 2011).

11. Finnell JA, Overhage JM, Grannis S. All healthcare is not local: an evaluation of distributed emergency department care delivery. AMIA Annu Symp Proc 2011;2011:409-16.

12. Gandhi TK, Sittig D, Franklin $M$, et al. Communication breakdown in the referral process. J Gen Intern Med 2000;15:626-31.

13. Womack S. Brown: NHS needs better out-of-hours care. The Telegraph. London: UK News, 2007. http://www.telegraph.co.uk/news/uknews/1552681/Brown-NHSneeds-better-out-of-hours-care.html (accessed 17 Oct 2011).

14. Overhage JM, Dexter PR, Perkins SM, et al. A randomized, controlled trial of clinical information shared from another institution. Ann Emerg Med 2002:39:14-23.

15. Unerti K, Johnson KB, Lorenzi NM. Health information exchange technology on the front lines of healthcare: workflow factors and patterns of use. J Am Med Inform Assoc 2012;19:392-400.

16. Vest JR, Zhao H, Jasperson J, et al. Factors motivating and affecting health information exchange usage. J Am Med Inform Assoc 2011:18:143-9.

17. Greenhalgh T, Stramer K, Bratan T, et al. Adoption and non-adoption of a shared electronic summary record in England: a mixed-method case study. BMJ 2011;340: c3111.

18. Johnson KB, Unertl KM, Chen 0 , et al. Health information exchange usage in emergency departments and clinics: the who, what and why. J Am Med Inform Assoc 2011:18:690-7.

19. Ciriello JN, Kulatilaka N. Smart health community: the hidden value of health information exchange. Am J Manag Care 2010;16(12 Suppl HIT):SP31-6.

20. Shapiro JS, Mostashari F, Hripcsak G, et al. Using health information exchange to improve public health. Am J Public Health 2011;101:616-23.

21. NHIN Cooperative DURSA Workgroup. DRAFT Data Use and Reciprocal Support Agreement (DURSA) Developed by: NHIN Cooperative DURSA Workgroup. Washington, DC: Office of the National Coordinator for Health Information Technology, 2009. http://healthit.hhs.gov/portal/server.pt/gateway/ PTARGS $01073184989100 \quad$ 18/DRAFT\%20NHIN\%20Trial\%20lmplementations \%20Production\%20DURSA-3.pdf (accessed 17 Oct 2011).
22. Adler-Milstein J, McAfee AP, Bates DW, et al. The State of regional health information organizations: current activities and financing. Health Aff (Millwood) 2008;27:w60-9.

23. Adler-Milstein J, Bates DW, Jha AK. A survey of health information exchange organizations in the United States: implications for meaningful use. Ann Intern Med 2011:154:66-71.

24. Office of the National Coordinator. Federal Health Information Technology Strategic Plan 2011-2015. Washington DC: Department of Health and Human Services. http://web.mediacdt.com/onc-emerg/FINAL-Federal-Health-IT-StrategicPlan-0911.pdf (accessed 17 Oct 2011).

25. President's Council of Advisors on Science and Technology. A report to the president: realizing the full potential of health information technology to improve the healthcare of Americans: the path forward. Washington DC: Executive Office of the President, 2010. http://www.whitehouse.gov/sites/default/files/microsites/ostp/ pcast-health-it-report.pdf (accessed 17 Oct 2011).

26. Stead WW, Kelly BJ, Kolodner RM. Achievable steps toward building a national health information infrastructure in the United States. J Am Med Inform Assoc 2005:12:113-29.

27. PCAST Workgroup. Draft PCAST Report Workgroup Letter. Office of the Nationa Coordinator for Health Information Technology, 2011. http://healthit.hhs.gov/portal/ server.pt/gateway/PTARGS 0 12811_954356_0_0_18/pcast-wg-draft-letter-04-13 11.pdf (accessed 17 Oct $201 \overline{1}$ ).

28. Conn J. PCAST Report Criticism Abounds at Hearing. Modern Healthcare, 2011 http://www.modernhealthcare.com/article/20110216/NEWS/ 110219967\#ixzz1VaZCHRAS (accessed 17 Oct 2011).

29. Terry K. Surescripts, AAFP Launch Secure Clinical Messaging Service for Doctors FierceMarkets, 2011. http://www.fiercehealthit.com/story/surescripts-aafp-launchsecure-clinical-messaging-service-doctors/2011-02-15\#ixzz1JN0jMsOi laccessed 17 Oct 2011)

30. VisionShare. VisionShare to Connect Nation's Healthcare Providers on Its Secure, Trusted Network. VisionShare, 2011. http://directability.visionshareinc.com/Releases/ Ability-11-02-02-Release.pdf (accessed 12 Apr 2011).

31. Dimick C. Seeking the united state of HIEs: connecting information exchange efforts is ONC's next challenge. J AHIMA 2011:82:28-32.

32. Adler-Milstein J, Landerfeld J, Jha AK. Characteristics associated with regional health information organization viability. J Am Med Inform Assoc 2010;17:61-5.

33. Grieve WA, Levin SL. Common carriers, public utilities and competition. Ind Corp Change 1996;5:993-1011. http://icc.oxfordjournals.org/content/5/4/993.full.pdf

34. Schultze CL. The Public Use of Private Interest. Washington, DC: Brookings Institution Press, 1977

35. Christensen C. The Innovator's Prescription: A Distruptive Solution for Healthcare. New York: McGraw Hill, 2009.

36. Chistensen C. Key Concepts -Disruptive Innovation. 2011. http://www. claytonchristensen.com/disruptive innovation.html (accessed 19 Aug 2011). 